\title{
Sustainable product design assessment combining the fuzzy theory and grey correlation analysis method
}

\author{
Feng Chunhua ${ }^{1, a}$,Wang Qibing ${ }^{2,3, b}$ \\ ${ }^{1}$ School of Mechanical Engineering, University of Shanghai for Science and Technology, Shanghai \\ 200093 \\ ${ }^{2}$ School of mechanical engineering, TianjinUniversity, Tianjin 300072 \\ ${ }^{3}$ Senhe Elevator Co. Ltd, Huzhou 313009 \\ afengchunhua333@163.com, ${ }^{b}$ 43410697@qq.com
}

\begin{abstract}
Keywords:sustainable design; sustainability assessment; fuzzy theory; grey correlation analysis Abstract.Sustainable product design has become significant factor for customers' selection, whereas it is difficult to evaluate sustainability with imprecise, vague and uncertain information. This paper proposes sustainable design performance assessment model integrating fuzzy theory and grey correlation analysis method considering fuzziness, uncertainty, correlation and coupling characteristics of evaluation index. The multi-level hierarchical structure is established to conduct a more effective analysis through defining sustainability criteria and sub-criteria. Furthermore, the fuzzy theory is utilized to determine weights of criteria and sub-criteria to improve the accuracy of assessment result and eliminate redundancy and fuzziness of the evaluating indices. Then, grey correlation analysis method is employed to present the correlation degree between reference sequences and comparative sequences involving all criteria and sub-criteria. Meanwhile, the product multi-level comprehensive sustainability index is obtained integrating all factors in every level by superposition to provide accurate for design, evaluation and solve the redundancy and imprecise problems. Finally, sustainability assessment of the elevator as case study to verify the effectiveness of the proposed method.
\end{abstract}

\section{Introduction}

Product designers normally focus on appearance, performance, cost, and durability [1]. However, the issue of sustainability in the mechanical and electrical products domain [2] has become a source of increasing concern and one of the main evaluating indicators in sustainability assessment. As a result, designers are frequently focusing on how to create more environmentally-friendly products. Currently, designers pay much attention to the later stage design phase when performing an environmental impact assessment. Designers conduct a Life Cycle Assessment (LCA) [3] of the product and optimize the design to reduce its environmental impacts, or even just use LCA for reporting after the specific design has been finalized including material selection, manufacturing process, and so on. However, this procedure is time consuming, with little positive impact. By contrast, designers in early-stage design have more flexibility in balancing sustainability and functionality. When the design parameters are not yet decided, designers and manufacturers have great potential to reduce the environmental impacts of product during whole life cycle. Therefore, a newer and more effective method needs to be established that can help designers to better incorporate sustainability during early-stage design.

Design for Environment (DfE) guidelines is a mean to provide advice and suggestions on how to improve the environmental and sustainability footprint throughout the design process. Oehlberg et al. [4] gathered more than 600 DfE principles from different regulations and papers. Although the guidelines are well sorted and classified in spreadsheets, many guidelines overlap and are also difficult to apply. Therefore, the current DfE guidelines by themselves cannot provide designers with enough helpful advice in the early stages of product design.Currently, different methods considering one, two or an integration of all dimensions of sustainability through main indicators or criteria have been developed by various researchers. The product design information at design phase is often vague, uncertain and interactive, whereas designers or engineers have to decide the best design alternative. 
Hence, it is need more hybrid methods or tools to make decision in design or selection process. Fuzzy theory (FT) has been employed to solve multiple criteria problem [5], which has the advantage to deal with vagueness, uncertainty and interdependence simultaneously. The weighted fuzzy assessment method is presented using fuzzy AHP and fuzzy logic approach through dealing with expert knowledge [6]. FT method can provide more precise assessment results using mathematical approach, and it will help decision makers to easily decide on which product alternative more sustainable.

To sum up, insufficient knowledge and a lack of useful tools often limit creative approaches to solve related problems although sustainable issues is growing. The main contribution of this paper is sustainable product design performance index (SPDPI) to assist engineers to assessment and select the better sustainable design scheme in proposed model. The purpose is to provide a decision support approach for engineers or designers in support of evaluation and comparison the relative performance of sustainable product design projects. The structure of this paper is as follows: (1) Model hierarchical multi-criteria structure with respect to sustainable product design criteria; (2) Establish sustainable assessment model using fuzzy theory and grey correlation analysis. To demonstrate the feasibility of the proposed methodology, sustainability assessment of the elevator as case study.

\section{Hierarchy structure of multi-level sustainability criteria}

Sustainability criteria need to be investigated to evaluate the sustainable performance of product. In this research, the sustainable product design factors are identified through interview, investigate and survey. The broadly accepted sustainability definition covers environment, economy and society known as the triple bottom line. Previous research referring to product assessment introduces mainly environmental aspect, even though economic and social factors are occasionally mentioned. This paper adds technology to assessment model because consumers also focus on function ability. The significant impact factors including quantitative criteria and qualitative attributes are identified, and then they can be translated into quantification form. Three levels criteria structure is established as shown in Fig.1.

\section{Sustainable assessment model using fuzzy theory and grey correlation analysis (FGCA)}

This section describes the calculation process of SPDPI utilizing fuzzy theory and grey correlation analysis method to assess sustainable product design performance. Fig. 2 shows how to calculate the SPDPI.The procedure for FGCA is described as follows.

Step 1: Determination of weights. Weight is an important factor for multi-criteria decision-making, and subjective and objective weights are considered in this paper. The fuzzy decision matrix is described using matter-element as

$$
X=\left[\begin{array}{ccccc}
c_{1} & c_{2} & \multicolumn{2}{c}{c_{n}} \\
A D S 1 & x_{11} & x_{12} & \cdots & x_{1 n} \\
A D S 2 & x_{21} & x_{22} & \cdots & x_{2 n} \\
\cdots & \cdots & \cdots & \cdots & \cdots \\
A D S m & x_{m 1} & x_{m 2} & \cdots & x_{m n}
\end{array}\right] \mathrm{X}=\left[\begin{array}{c}
\mathrm{c}_{1} \mathrm{c}_{2} \cdots \mathrm{c}_{\mathrm{n}} \\
\mathrm{ADS}_{1} \mathrm{x}_{11} \mathrm{x}_{12} \cdots \mathrm{x}_{1 \mathrm{n}} \\
\mathrm{ADS}_{2} \mathrm{x}_{21} \mathrm{x}_{22} \cdots \mathrm{x}_{2 \mathrm{n}} \\
\cdots \cdots \cdots \cdots \cdots \\
\mathrm{ADS}_{\mathrm{m}} \mathrm{x}_{\mathrm{m} 1} \mathrm{x}_{\mathrm{m} 2} \cdots \mathrm{x}_{\mathrm{mn}}
\end{array}\right](1)
$$

where $c_{n}$ is the characteristic of sustainable design assessment, ADSmis the evaluated scheme, $x$ is the value of corresponding characteristic.Each characteristiccould have sub-criteria. For elevator's environmental performance can be described as

\begin{tabular}{|c|c|c|c|c|c|}
\hline \multirow{4}{*}{$X_{\mathrm{ENI}}=$} & & \multicolumn{2}{|c|}{ ENIF1ENIF2 } & ENIF3 & ENIF4 \\
\hline & $A D S 1$ & 34 & 78.7 & 57.2 & 53.8 \\
\hline & $A D S 2$ & 72 & 77.8 & 64.9 & 63.9 \\
\hline & LADS3 & 20.9 & 68.2 & 61.2 & 54.6 \\
\hline
\end{tabular}

where ENIF1 is rated power, ENIF2 is noise of engine room, ENIF3 is noise of open and shut down, and ENIF4 is noise of lift car. The fuzzy reciprocal judgment matrix for criteria is expressed as

where $u_{i j}$ is the importance degree of pairwise comparison for criteria or sub-criteria.

$$
U=\left[\begin{array}{cccc}
u_{11} & u_{12} & \cdots & u_{1 n} \\
u_{21} & u_{22} & \cdots & u_{2 n} \\
\cdots & \cdots & u_{i j} & \cdots \\
u_{n 1} & u_{n 2} & \cdots & u_{n n}
\end{array}\right](2)
$$




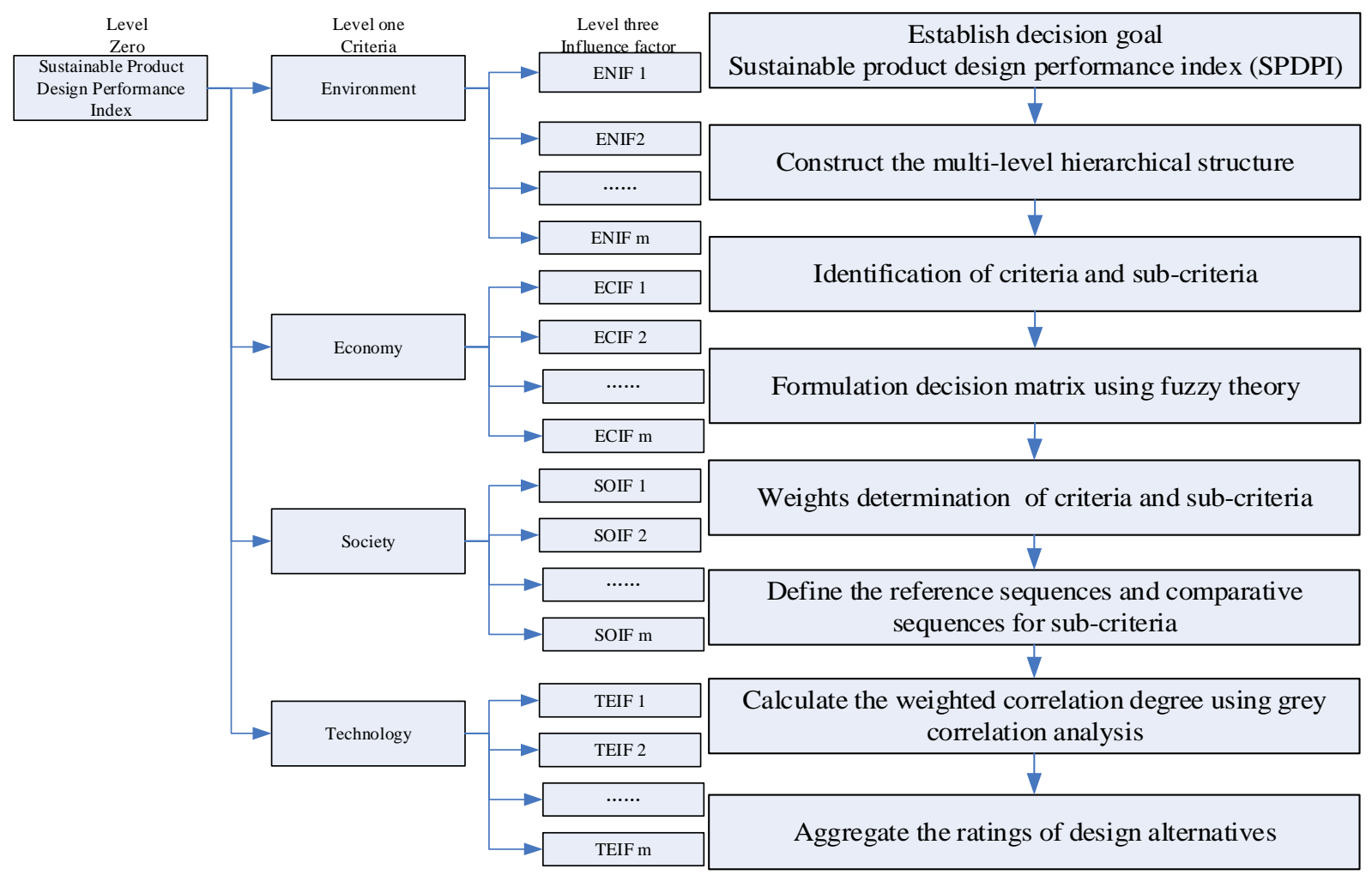

Fig. 1 The multi-level hierarchical structure

Fig.2 The flowchart of FGCA

According to minimum distance principle, the following linear programming model for subjective and objective are established respectively as

$$
\begin{gathered}
\operatorname{minz}_{1}=\sum_{i=1}^{n} \sum_{j=1}^{n}\left(u_{i j} \omega_{j}-\omega_{i}\right)^{2} \\
\operatorname{minz}_{2}=\sum_{i=1}^{m} \sum_{j=1}^{n}\left(x_{j}^{*}-x_{i j}\right)^{2} \omega_{j}^{2}
\end{gathered}
$$

where $\sum_{j=1}^{n} \omega_{j}=1, \quad \omega_{j} \geq 0, j=1,2, \cdots, n . x_{j}^{*}=\max \left\{\left(x_{i j} \mid i=1,2, \cdots, m\right)\right\}, j=1,2, \cdots, n$.

There $\alpha$ and $\beta$ represent the coefficients of subjective and objective weights respectively. We can get the integrated model is describedasminz $=\alpha \sum_{i=1}^{n} \sum_{j=1}^{n}\left(u_{i j} \omega_{j}-\omega_{i}\right)^{2}+\beta \sum_{i=1}^{m} \sum_{j=1}^{n}\left(x_{j}^{*}-x_{i j}\right)^{2} \omega_{j}^{2}$. where $\alpha, \beta \in[0,1]$ and $\alpha+\beta=1$.

Using mathematical program for solving the problem, we can get the integrated weight as

where $Q=\left[q_{i j}\right]_{n \times n}$, and $q_{i j}=-\alpha \sum_{i=1}^{n} \sum_{j=1}^{n}\left(u_{i j}+u_{j i}\right), i, j=1,2, \cdots, n ; i \neq j$,

$$
\omega=\frac{Q^{-1} e}{e^{T} Q^{-1} e}
$$

$$
q_{i i}=\sum_{j=1}^{n}\left[\alpha\left(\sum_{i=1}^{n} u_{i j}^{2}+n-2\right)+\beta \sum_{i=1}^{m}\left(x_{j}^{*}-x_{i j}\right)^{2}\right], i=1,2, \cdots, n . \mathrm{e}=(1,1, \cdots, 1)^{T} .
$$

Step 2: Calculating correlation degree. The grey correlation analysis method is employed to calculate correlation degree between reference sequencesand comparative sequences. Assume that the reference sequence $\mathrm{X}_{0}$ for criteria is described as

The $m$ comparative sequences is

Then correlation degree is

$$
\begin{aligned}
X_{0} & =\left\{X_{0}(k) \mid k=1,2, \cdots, n\right\}=\left(X_{0}(1), X_{0}(2), \cdots, X_{0}(n)\right)(6) \\
X_{i} & =\left\{X_{i}(k) \mid k=1,2, \cdots, n\right\}=\left(X_{i}(1), X_{i}(2), \cdots, X_{i}(n)\right)(7) \\
\xi_{i}(k) & =\frac{\min _{i} \min _{k}\left|X_{0}(k)-X_{i}(k)\right|+\rho \max _{i} \max _{k}\left|X_{0}(k)-X_{i}(k)\right|}{\left|X_{0}(k)-X_{i}(k)\right|+\rho \max _{i} \max _{k}\left|X_{0}(k)-X_{i}(k)\right|}(8)
\end{aligned}
$$

where $\min _{i} \min _{k}\left|X_{0}(k)-X_{i}(k)\right|, \max _{i} \max _{k}\left|X_{0}(k)-X_{i}(k)\right|$ is the double minimum and biggest difference respectively. $\rho$ is the identification coefficient and general is 0.5 .

The integrated correlation degreeis expressed as

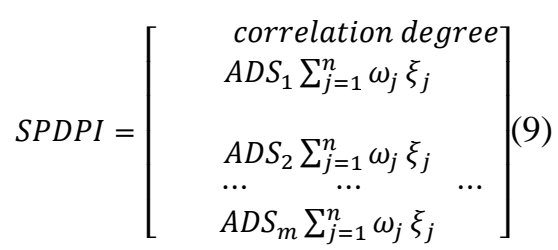




\section{Case Study}

The sustainability and energy conservation of elevator will promote the elevator industry to create new energy technology progress. This paper takes the elevator sustainability evaluation as an example, and identifies criteria and sub-criteria as shown in Table1.

Table 1 Sustainability indicator for elevator

\begin{tabular}{|l|l|}
\hline Criteria & Sub-criteria \\
\hline TEI: Technology & $\begin{array}{l}\text { TEIF1: Rated speed, TEIF2:Pulley diameter, TEIF3:Open time, TEIF4:Closing time, } \\
\text { TEIF5:Leveling accuracy }\end{array}$ \\
\hline $\begin{array}{l}\text { ENI } \\
\text { Environment }\end{array}$ & $\begin{array}{l}\text { ENIF1: Rated power, ENIF2:Noise of Engine room, ENIF3: Noise of open and shut down, } \\
\text { ENIF4: Noise of lift car }\end{array}$ \\
\hline SOI: Society & $\begin{array}{l}\text { SOIF1:Acceleration and deceleration, SOIF2:Vertical vibration, SOIF3:Horizontal } \\
\text { vibration }\end{array}$ \\
\hline ECI: Economy & $\begin{array}{l}\text { ECIF1:Usability performance, ECIF2: Maintenance performance, ECIF3:Rated loading } \\
\text { capacity }\end{array}$ \\
\hline
\end{tabular}

Parameters of three series of elevator is collected as shown in Table 2.

Table 2 Parameters of three series of elevator

\begin{tabular}{|l|l|l|l|}
\hline & Series 1 & Series 2 & Series 3 \\
\hline Rated speed $(\mathrm{m} / \mathrm{s})$ & 3.5 & 7.0 & 2.0 \\
\hline Rated loading capacity $(\mathrm{kg})$ & 1250 & 1600 & 1600 \\
\hline Pulley diameter $(\mathrm{mm})$ & 480 & 800 & 450 \\
\hline Rated power $(\mathrm{kw})$ & 34 & 72 & 20.9 \\
\hline Average acceleration and deceleration $\left(\mathrm{m} / \mathrm{s}^{2}\right)$ & 0.416 & 0.949 & 0.625 \\
\hline Open time $(\mathrm{s})$ & 3.24 & 2.7 & 3.5 \\
\hline Closing time $(\mathrm{s})$ & 4.28 & 2.7 & 3.5 \\
\hline Vertical vibration $\left(\mathrm{cm} / \mathrm{s}^{2}\right)$ & 0.128 & 0.128 & 0.148 \\
\hline Horizontal vibration $\left(\mathrm{cm} / \mathrm{s}^{2}\right)$ & 0.084 & 0.084 & 0.152 \\
\hline Leveling accuracy $(\mathrm{mm})$ & 6 & 6 & 4 \\
\hline Noise of Engine room $(\mathrm{dB})$ & 78.7 & 77.8 & 68.2 \\
\hline Noise of open and shut down $(\mathrm{dB})$ & 57.2 & 64.9 & 61.2 \\
\hline Noise of lift car $(\mathrm{dB})$ & 53.8 & 63.9 & 54.6 \\
\hline
\end{tabular}

According to procedure of proposed assessment model, we can get evaluation matrix with criteria and sub-criteria as follows.

$$
\begin{aligned}
\mathrm{TEI} & =\left[\begin{array}{cccccc}
\text { TEIF1 TEIF2 TEIF3 } & \text { TEIF4 } & \text { TEIF5 } \\
A D S 1 & 3.5 & 480 & 3.24 & 4.28 & 6 \\
A D S 2 & 7 & 800 & 2.7 & 2.7 & 6 \\
A D S 3 & 2 & 450 & 3.5 & 3.5 & 4
\end{array}\right], \mathrm{ENI}=\left[\begin{array}{cccccc}
\text { ENIF1 } & \text { ENIF2 } & \text { ENIF3 } & \text { ENIF4 } \\
A D S 1 & 34 & 78.7 & 57.2 & 53.8 \\
A D S 2 & 72 & 77.8 & 64.9 & 63.9 \\
A D S 3 & 20.9 & 68.2 & 61.2 & 54.6
\end{array}\right], \\
\mathrm{SOI} & =\left[\begin{array}{ccccc}
\text { SOIF1 } & \text { SOIF2 } & \text { SOIF3 } \\
A D S 1 & 0.416 & 0.128 & 0.084 \\
A D S 2 & 0.949 & 0.128 & 0.084 \\
A D S 3 & 0.625 & 0.148 & 0.152
\end{array}\right], \mathrm{ECI}=\left[\begin{array}{cccc}
E C I F 2 & \text { ECIF3 } \\
A D S 1 & \tilde{5} \tilde{5} & 1250 \\
A D S 2 & \tilde{4} \tilde{4} & 1600 \\
A D S 3 & \tilde{3} \tilde{3} & 1600
\end{array}\right] .
\end{aligned}
$$

The fuzzy comparative matrix are shown in Tables $3 \sim 6$. Weight of influnce factors are shown in Fig.3.

Table 3 Correlation matrix of sub-criteria for technical performance

\begin{tabular}{|l|l|l|l|l|l|}
\hline & TEIF1 & TEIF2 & TEIF3 & TEIF4 & TEIF5 \\
\hline TEIF1 & $(1,1,1)$ & $(4,5,6)$ & $(6,7,8)$ & $(6,7,8)$ & $(4,5,6)$ \\
\hline TEIF2 & $(1 / 6,1 / 5,1 / 4)$ & $(1,1,1)$ & $(2,3,4)$ & $(2,3,4)$ & $(1 / 3,1 / 2,1)$ \\
\hline TEIF3 & $(1 / 8,1 / 7,1 / 6)$ & $(1 / 4,1 / 3,1 / 2)$ & $(1,1,1)$ & $(1,1,1)$ & $(1 / 3,1 / 2,1)$ \\
\hline TEIF4 & $(1 / 8,1 / 7,1 / 6)$ & $(1 / 4,1 / 3,1 / 2)$ & $(1,1,1)$ & $(1,1,1)$ & $(1 / 3,1 / 2,1)$ \\
\hline TEIF5 & $(1 / 6,1 / 5,1 / 4)$ & $(1,2,3)$ & $(1,2,3)$ & $(1,2,3)$ & $(1,1,1)$ \\
\hline
\end{tabular}

Table 4 Correlation matrix of sub-criteria for environmental performance

\begin{tabular}{|l|l|l|l|l|}
\hline & ENIF1 & ENIF2 & ENIF3 & ENIF4 \\
\hline ENIF1 & $(1,1,1)$ & $(6,7,8)$ & $(4,5,6)$ & $(2,3,4)$ \\
\hline ENIF2 & $(1 / 8,1 / 7,1 / 6)$ & $(1,1,1)$ & $(1 / 4,1 / 3,1 / 2)$ & $(1 / 8,1 / 7,1 / 6)$ \\
\hline ENIF3 & $(1 / 6,1 / 5,1 / 4)$ & $(2,3,4)$ & $(1,1,1)$ & $(1 / 10,1 / 9,1 / 8)$ \\
\hline ENIF4 & $(1 / 4,1 / 3,1 / 2)$ & $(6,7,8)$ & $(8,9,10)$ & $(1,1,1)$ \\
\hline
\end{tabular}


Table5 Correlation matrix of sub-criteria for society performance

\begin{tabular}{|l|l|l|l|}
\hline & SOIF1 & SOIF2 & SOIF3 \\
\hline SOIF1 & $(1,1,1)$ & $(4,5,6)$ & $(6,7,8)$ \\
\hline SOIF2 & $(1 / 6,1 / 5,1 / 4)$ & $(1,1,1)$ & $(2,3,4)$ \\
\hline SOIF3 & $(1 / 8,1 / 7,1 / 6)$ & $(1 / 4,1 / 3,1 / 2)$ & $(1,1,1)$ \\
\hline
\end{tabular}

Table 6 Correlation matrix of sub-criteria for economy performance

\begin{tabular}{|c|c|c|c|}
\hline & ECIF1 & ECIF2 & ECIF3 \\
\hline ECIF1 & $(1,1,1)$ & $(2,3,4)$ & $(2,3,4)$ \\
\hline ECIF2 & $(1 / 4,1 / 3,1 / 2)$ & $(1,1,1)$ & $(1,1,1)$ \\
\hline ECIF3 & $(1 / 4,1 / 3,1 / 2)$ & $(1,1,1)$ & $(1,1,1)$ \\
\hline
\end{tabular}

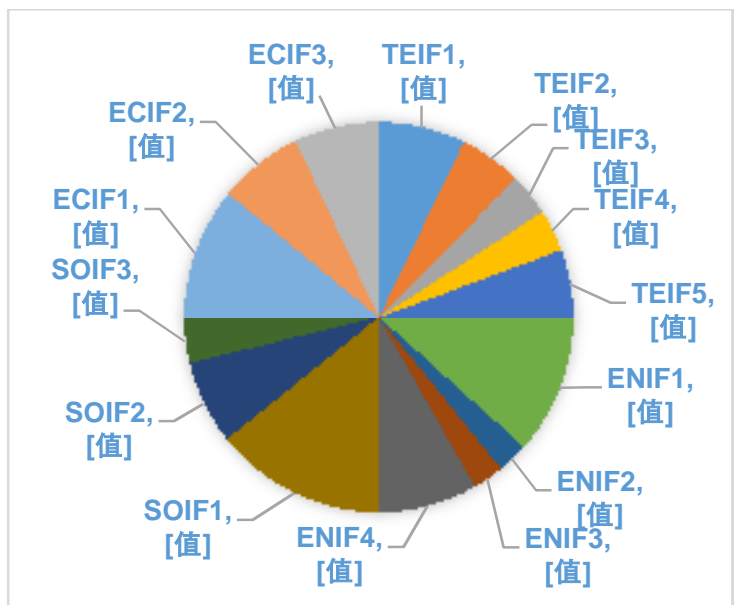

Fig.3 Weight of influnce factors

Dimensionless of all criteria are descirbed as:

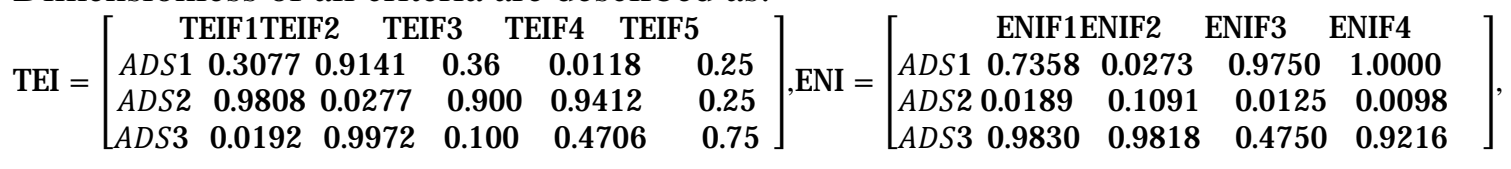

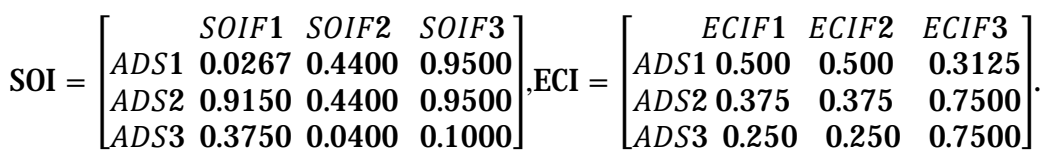

Influence factors value of different series product is shown in Fig.4.

The result of SPDPI for different series product is shown in Fig.5, the value is:

SPDPI $=\left[\begin{array}{ccccc} & T E I & E N I & S O I & E C I \\ A D S 1 & 0.3875 & 0.7697 & 0.2821 & 0.4473 \\ A D S 2 & 0.6000 & 0.0247 & 0.7880 & 0.4805 \\ A D S 3 & 0.4623 & 0.9160 & 0.2399 & 0.3606\end{array}\right]$, SPDPI $=\left[\begin{array}{cc}\multicolumn{2}{c}{\text { Correlation degree }} \\ A D S 1 & 0.4717 \\ A D S 2 & 0.4733 \\ A D S 3 & 0.5022\end{array}\right]$.

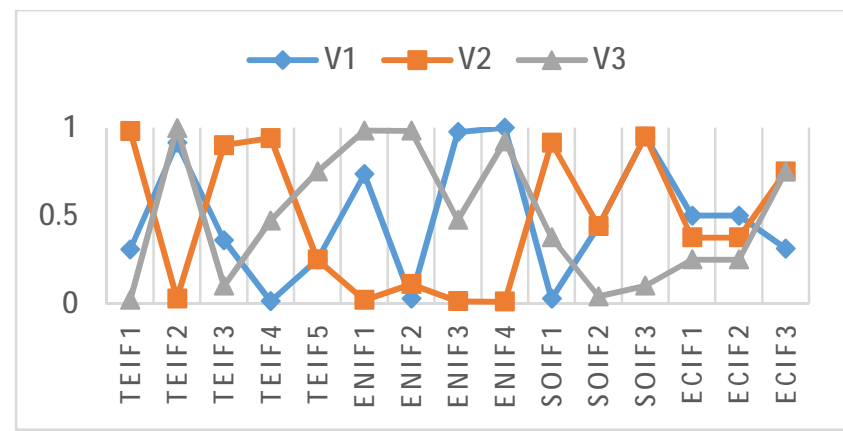

Fig.4 Influence factors value

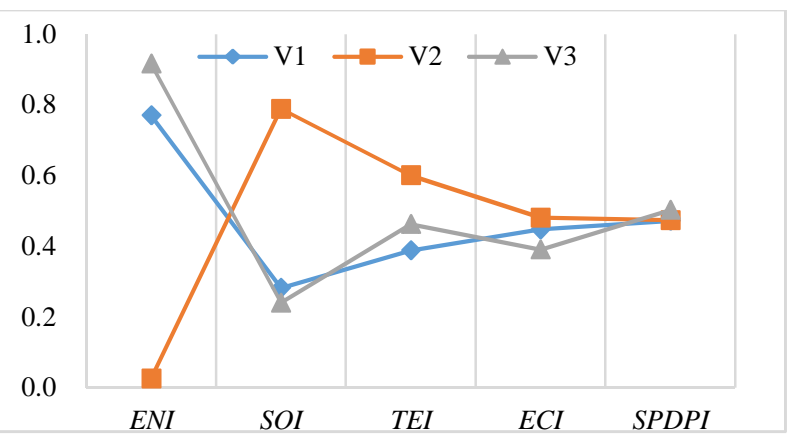

Fig.5 The result of SPDPI

From the results of Fig. 5, we can conclude that:

(1) Poduct series 3 has the better sustainability performance than series 1 and 2 . The ranking of environmental performance is series $3>1>2$; social performance is series $2>1>3$; technology performance is series $2>3>1$; economy performance is series $2>1>3$. 
(2) Product series 2 has the advantage on technology, social and economy, whereas the environmental performance is poor. Hence, the comprehensive sustainability performance is a little lower than series 3 .

(3) Product series 1 is general in all sorts of performance without prominent, and comprehensive performance is slightly lower than the product series 2 .

To sum up, the result of sustainable performance of different products can be feedback to the design parameters. According to the specific conditions of use, the choice of final solution is determined by policy makers to optimize the design parameters of the scheme.

\section{Conclusions}

In this paper, product sustainable design performance assessment model is established using fuzzy theory and grey correlation analysis method. The integrated weights of sustainability criteria and sub-criteria are determined considering subjective and objective factors. Moreover, correlation degree of reference sequences and comparison sequences in multi-dimension is calculated using grey correlation analysis. SPDPI is obtained through recursive aggregation on each hierarchical level. When considering more criteria, it could achieve better sustainability performance in the same conditions. The application of case study proves the necessary for considering integrated sustainability aspects.

\section{Acknowledgements}

This work was financially supported by the National Natural Science Foundation of China (Grant No.51605294), Shanghai teacher training scheme (ZZs115027) and Shanghai Municipal Education Commissionindustry-university-research cooperation project.

\section{References}

[1] P.Knight, J.O.Jenkins: Journal of Cleaner Production Vol. 17 (2009), p. 549-558

[2] C.CHuang, H.W.Ma: Science of the Total EnvironmentVol. 324 (2004), p. 161

[3] P.A. Roy: Journal of Food Engineering Vol. 90(2009), p. 1-10

[4] L.Oehlberg, C.Bayley, C. Hartman and A.Agogino:Mapping the Life Cycle Analysis and Sustainability Impact of Design for Environment Principles(Springer Berlin Heidelberg, 2012).

[5] C.W. Chang, C.R. Wu, C.T. Lin andH.C. Chen: Computers \& Industrial EngineeringVol. 52(2007), p. 296-307

[6] Z.Taha, S.Rostam: Journal of Intelligent ManufacturingVol. 23 (2012), p. 2137-2149 